\title{
Appraisal of Emotions in Media Use: Towards a Process Model of Meta-Emotion and Emotion Regulation
}

\author{
Anne Bartsch ${ }^{1}$, Peter Vorderer ${ }^{2}$, Roland Mangold $^{3}, \&$ Reinhold Viehoff ${ }^{4}$ \\ ${ }^{1}$ Martin Luther University Halle, Germany \\ ${ }^{2}$ VU University Amsterdam, The Netherlands \\ ${ }^{3}$ Stuttgart Media University, Germany \\ ${ }^{4}$ Martin Luther University Halle, Germany
}

Bartsch, A., Vorderer, P., Mangold, R., \& Viehoff, R. (2008). Appraisal of emotions in media use: Toward a process model of meta-emotion and emotion regulation. Media Psychology, 11(1), 7-27. doi:10.1080/15213260701813447

The definitive version is available at

http://www.tandfonline.com/doi/full/10.1080/15213260701813447

This article may not exactly replicate the final version published in the previously mentioned Journal. It is not the version of record and is therefore not suitable for citation.

Acknowledgements: The authors wish to thank Robin Nabi and the anonymous reviewers for their helpful comments on earlier drafts of this paper.

\section{Funding: -}

Corresponding author: anne.bartsch@medienkomm.uni-halle.de 


\begin{abstract}
Over the past 20 years, research on meta-emotion and related concepts such as metamood and need for affect has become fruitful and prominent across a variety of disciplines, including media psychology in particular. This paper reviews the literature on meta-emotion and considers problems regarding the definition and operationalization of this construct. We propose a process model of meta-emotion and emotion regulation to integrate and extend existing work. Drawing on appraisal theories of emotion, we understand meta-emotion as a process that monitors and appraises emotions, recruits affective responses toward them, which results in a motivation to maintain and approach emotions, or to control and avoid them. This meta-emotion process plays an important role in media users' selection or rejection of specific media offerings and their invitation to experience emotion. We discuss how this framework may integrate previously unrelated findings on the role of emotions in guiding selective media use and conclude with directions for further research.
\end{abstract}

Keywords: appraisal of emotion, meta-emotion, emotion regulation, selective media use 
Appraisal of emotions in media use 3

Appraisal of Emotions in Media Use:

Towards a Process Model of Meta-Emotion and Emotion Regulation ${ }^{1}$

"the only thing we have to fear is fear itself",

Roosevelt's famous words on the fear of fear point to humans' ability to have emotions about emotions much like they can have thoughts about thoughts. Drawing on an analogy with meta-cognition, authors like Mayer and Gaschke (1988), Oliver (1993) and Gottman, Katz, and Hooven (1997) have coined the term meta-emotion to refer to this phenomenon. Since then, researchers actively have examined meta-emotion and related areas (meta-mood, need for affect, and fear of emotions) across a variety of disciplines, including media psychology, personality research, child development, clinical psychology, attitude research, consumer research, and others.

The common thread behind meta-emotion and related concepts is that people experience, evaluate, and deal with emotion in substantially different ways (Gottman et al., 1997; Maio \& Esses, 2001; Mayer \& Gaschke, 1988; Oliver, 1993). "Some like it hot" (Appel, in press, p. 1) whereas others could well do without the highs and lows of emotion. Some people feel easily "flooded" (Gottman, 1994, p. 21) or overwhelmed by emotions, whereas others are more confident in their ability to regulate emotions and to express them in socially appropriate ways. Besides these inter-individual differences, a given individual's willingness and ability to derive gratification from the experience of emotion may differ depending on the situation. Feeling sad while watching the final scene of Casablanca (USA, 1942) is a rewarding experience to many people, whereas feeling sad about losing love in one's own life is usually not.

Such differences in the experience and expression of emotion have led a number of authors to conclude that sadness is not equal to sadness, anger is not equal to anger, and so on. Rather, emotions are accompanied by meta-level mental processes that color the 
Appraisal of emotions in media use 4

experience of emotions and influence how people express and regulate them. Meta-processes seem able even to modify what is often considered to be the most fundamental aspect of emotional experience - its hedonic valence (cf., Oliver, 1993). So-called "negative emotions" like anger, fear and sadness can sometimes be a rewarding experience-as with righteous indignation, thrill or bittersweet melancholy_and "positive emotions" like joy and love are at times unwelcome - as with guilty pleasures or unwanted infatuation (cf., Jäger \& Bartsch, 2006).

In this paper we first provide an overview of recent research on meta-emotion and related constructs that highlights the concept's broad and successful application. We then consider difficulties concerning the definition and operationalization of mental processes that count as meta-emotion. Further we propose an integrative approach that may help clarify some of the problematic issues and develop a more systematic framework for describing meta-emotion in the context of media use. We do so by revisiting meta-emotion in the context of general emotion theory, with a special focus on appraisal theories of emotion. Building on recent theoretical conceptualizations proposed by Bartsch, Mangold, Viehoff, and Vorderer (2006) and Wirth and Schramm (2007), we offer an extended process model of meta-emotion and emotion regulation during media use. We discuss how this framework can help integrate previously unrelated findings on the role of emotions in guiding selective media use and conclude with directions for further research.

\section{Research Overview}

The seminal work of Mayer and Gaschke (1988) defines meta-mood as "the possible outcome of a regulatory process that monitors, evaluates, and changes mood" (p.109). It is closely related to the concept of emotional intelligence, that is, individuals' "skill with which they can identify their feelings and the feelings of others, regulate these feelings, and use the information provided by their feelings to motivate adaptive behavior" (Salovey, Stroud, 
Appraisal of emotions in media use 5

Woolery, \& Epel, 2002, p. 611; cf., Salovey \& Mayer, 1990). These authors show that a selfconscious and self-controlled way of dealing with emotion (as measured by the Trait MetaMood Scale of Salovey, Mayer, Goldman, Turvey, \& Palfai, 1995) is associated with positive outcomes such as psychological well-being, social competence, and health (Goldman et al., 1996; Salovey et al., 1995; Salovey et al., 2002). In a similar vein, family researchers Gottman, Katz and Hooven (1997) found that a positive attitude toward emotions in parents predicted a number of positive outcomes in their children. Children who grew up in families with positive attitudes toward emotion were able to recover from physiological arousal more quickly, were less vulnerable to negative daily moods, engaged in cooperative peer play more often and had better academic achievement. Others have suggested that fear of emotions, poor emotional intelligence, and growing up in an emotion-dismissing family could contribute to a number of psychic and interpersonal problems, for example, relationship violence (Jakupcak, 2003), general anxiety disorder (Roemer, Salters, Raffa, \& Orsillo, 2005) and borderline personality disorder (Prairie, 2004).

A second line of research has studied meta-emotion in the context of media entertainment. Oliver (1993) proposes to solve "the paradox of the enjoyment of sad films" (p. 315) by considering people's taste for tragic entertainment a meta-emotion. She constructed a Sad Film Scale to measure preference for sad entertainment. For individuals who scored highly on this scale, greater reported sadness while watching sad film scenes was associated with greater reported enjoyment. Those who scored low on the scale, however, experienced the opposite. For them, sadness was negatively related to enjoyment. Oliver therefore concluded that feeling sad while watching melodramas is a rewarding experience for a specific (predominantly female) audience, whereas others find it rather aversive (see also, Oliver, Weaver, \& Sargent, 2000). Similarly, Appel (in press) found that Need for Affect (defined by Maio \& Esses, 2001 as the "general motivation of people to approach or 
Appraisal of emotions in media use 6

avoid situations and activities that are emotion inducing for themselves and others", p. 585) predicted individuals' motivation to watch films with affectively negative content. Results of Bartsch (2007) suggest that existing findings on meta-emotion in the context of sad entertainment might be extended to horror films. Participants' self-report of more positive meta-emotions during a horror movie was associated with a tendency to evaluate the movie more favorably.

Recently, the study of meta-emotion has been extended to fields like attitude research and consumer research. Maio and Esses (2001) constructed a measure of Need for Affect that assesses a person's motivation to approach and avoid emotion eliciting situations (see definition above). Need for Affect was shown, among other things, to predict attitude extremity, that is, the tendency to express either extremely positive or extremely negative opinions about a number of controversial issues (e.g., abortion, censorship, violent television programming, etc.). Marketing researchers Sojka and Giese (2001) studied sensitivities to different forms of persuasive communication. They found that people with a strong need for affect preferred to process visual information, whereas need for cognition was associated with a preference for verbal information. Last, but not least, the concept of meta-emotion has inspired theoretical work in a variety of other disciplines, including film studies (Bartsch \& Viehoff, 2003; Freeland, 1999), cultural history, and philosophy of mind (Ellis, 2005; Jäger \& Bartsch, 2006).

Although this research overview on meta-emotion and related constructs is far from exhaustive, it establishes the concept's explanatory value and predictive validity across a number of research fields-even across the divide between the humanities and the social sciences. However, despite its apparent success, the concept of meta-emotion is not entirely uncontroversial. One major difficulty with the concept is the lack of a commonly shared definition of the higher order mental states and processes that count as meta-emotion. A 
Appraisal of emotions in media use 7

second problem, which directly relates to definitional issues, concerns the operationalization of meta-emotion, as different interpretations of the concept have led to a variety of psychometric approaches.

\section{Definitions and Operationalizations of Meta-Emotion}

Does the term "meta-emotion" mean that people experience emotions about their own emotions? Or does it refer to any kind of cognitive, affective, volitional, and other mental states that are causally related to emotions and/or can take emotions as their intentional objects? Some authors consider meta-emotion a concept that exclusively refers to emotions and other affective reactions toward one's own emotions (e.g., Gottman et al., 1997; Jäger \& Bartsch, 2006; Maio \& Esses, 2001; Oliver, 1993; Williams, Chambless, \& Ahrens, 1997; Wirth \& Schramm, 2007). Others construe meta-emotion to include a wider range of metalevel mental processes, including emotional self-awareness, normative evaluation of emotions, emotion regulation, etc. (e.g., Mayer \& Gaschke, 1988; Mayer \& Stevens, 1994; Salovey et al., 1995).

Gottman et al. (1997) provide a prominent example of the stricter definition: "By meta-emotion we mean emotion about emotion." (p. 6). The Affect Control Scale (Williams et al., 1997) measures fear of emotion, which taps meta-emotion in this narrow sense. The items refer to the fear and worry of specific kinds of emotion and attempts to avoid these emotions. The Need for Affect Scale (Maio \& Esses, 2001) measures general tendencies to approach and avoid emotion-inducing situations and activities regardless of the type of emotion (e.g., "I feel that I need to experience strong emotions regularly.", "Emotions are dangerous - they tend to get me into situations that I would rather avoid."). Sojka and Giese (1997) and Raman, Chattopadhyay and Hoyer (1995) have operationalized need for affect and need for emotion, respectively, in a similar way. Oliver's (1993) Sad Film Scale addresses meta-emotion in a specific context — affective evaluation of sadness while watching 
Appraisal of emotions in media use 8

a film. The "entertainment index" (Unterhaltungsindex) of Früh, Wünsch and Klopp (2004) is another media-specific operationalization that measures entertainment as an affective response toward emotion.

In contrast, the broader interpretation does not require meta-processes involved in meta-emotion to be emotions themselves; rather, meta-emotion is considered to be a metaexperience of, or meta-cognition about emotion that may or may not involve an affective reaction toward the emotion in question. According to Oatley and Jenkins (1996) metaemotion is "what people think about emotions" (p. 305). Mayer and Gaschke (1988) describe meta-mood more precisely as a regulatory process that monitors, evaluates, and changes mood (p.109, see definition above).

The State and Trait Meta-Mood Scales developed by Mayer and Stevens (1994) and Salovey et al. (1995), respectively, operationalize meta-emotion using this more inclusive view. The State Meta-Mood-Scale consists of two domains: meta-evaluation and metaregulation. The subscales for meta-evaluation, followed by item examples, are: (1) Clarity ("I know exactly how I'm feeling."), (2) Acceptability ("I'm not ashamed of my mood."), (3) Typicality ("I feel this mood often."), and (4) Influence ("It's changed how I think."). The subscales for meta-regulation are: (5) Repair ("I'm thinking good thoughts to cheer myself up.”), (6) Maintenance (“I wouldn't want to change this mood.”), and (7) Dampening ("I distrust how positive this mood is, and I'm trying to bring it down.”). The Trait Meta-Mood Scale (Salovey et al., 1995) includes only three subscales: Attention, Clarity and Repair. If meta-emotion includes self-awareness and self-control of emotion, it may overlap with other constructs and their operationalizations, for instance, emotional intelligence (Mayer, Salovey, \& Caruso, 2002), affective orientation (Booth-Butterfield \& Booth-Butterfield, 1990), alexithymia (Taylor, Ryan \& Bagby, 1985), repression-sensitization (Byrne, 1996), coping 
Appraisal of emotions in media use 9

(Folkmann \& Lazarus, 1985), negative mood regulation (Catanzaro \& Mearns, 1990), difficulties in emotion regulation (Gratz \& Roemer, 2004), and others.

At least nine operationalizations of meta-emotion and related constructs exist, along with an even larger number of definitions. These operationalizations are not redundant; the only case of substantial overlap occurs among the three scales measuring need for affect / need for emotion that Raman et al. (1995), Sojka and Giese (1997) and Maio and Esses (2001) developed independently. The individual definitions and operationalizations differ not only with respect to inclusive versus narrow interpretation but also with regard to a number of other characteristics (see table 1).

$$
\text { -- insert table } 1 \text { about here -- }
$$

These differences in the definition and operationalization of meta-emotion seem not to be mere idiosyncrasies but reflections of the actual complexity of the subject matter. Metaemotion involves cognitive, affective and motivational aspects; most conceptualizations include at least two of these components, and some contain all three. Meta-emotions are considered both states and traits. According to Oliver (1993, p. 320), the experience of metaemotions leaves memory traces that result in a generalized disposition to react to emotions in a specific way (for a detailed discussion of stat and trait aspects of meta-emotion see Jäger \& Bartsch, 2006). Meta-emotional dispositions can pertain to emotions in general (e.g., an overall reluctance to indulge strong emotions) as well as to particular kinds of primary emotions and moods (e.g., a personal tendency to enjoy melancholic, but not anxious or irritated moods). Some of the meta-emotional dispositions seem to generalize widely across situations, whereas others are more context-specific (such as the enjoyment of sadness in the context of tragic entertainment, but not in everyday life). Further, mental processes involved in meta-emotion are not only valenced; they also include specific cognitive, affective and motivational content. 
Appraisal of emotions in media use 10

The complexities of meta-emotion and their consequences for definitional and operationalizational issues have not yet been discussed systematically, nor integrated into an overarching conceptual framework. Therefore, we propose a theoretical framework to advance this state of research, particularly with respect to the role of meta-emotion in media use.

\section{Meta-Emotion Revisited in the Context of Appraisal-Theories}

The research literature summarized above offers a number of concepts and theoretical explanations to account for meta-emotion. Instead of adding to the wealth of existing conceptual frameworks, we propose to consider meta-emotion in the most literal sense of the term-as a form of emotion. Recently, Mangold, Unz and Winterhoff-Spurk (2001), Bartsch et al. (2006) and Wirth and Schramm (2007) have proposed to consider meta-emotion in light of appraisal theories of emotion. Conceptualizing both emotion and meta-emotion in terms of emotion theory has the advantage of using theoretical frameworks parsimoniously. If metaemotion can be described as a special case of emotion, additional conceptual frameworks are unnecessary unless they contribute to the understanding of meta-emotion phenomena beyond the scope of emotion theory. We will briefly introduce the appraisal-theoretical approach and then discuss how it may help bring focus to the concept and aid in modeling systematic interactions of different aspects of meta-emotion. Further we address some limitations in how appraisal theories have been applied to meta-emotion thus far and propose an extended model of meta-emotion and emotion regulation in media use.

Appraisal theories of emotion (e.g., Frijda \& Zeeleberg, 2001; Lazarus, 1991; Scherer, 2001) assume that emotions are elicited by a person's appraisal of events with regard to his or her concerns. Appraisal criteria involved in eliciting emotion include the novelty and pleasantness of events, their goal conduciveness, controllability, and normative evaluation. A central tenet of appraisal theories states that emotions are not elicited by isolated stimuli, 
Appraisal of emotions in media use 11

objects, and events; rather, emotions are the result of appraisal processes that relate stimuli, objects and events to a person's needs and concerns. Concerns, in turn, are a function of individual disposition and situational context. For example, if a person scores high on achievement motivation (personal disposition) and is in an achievement situation (situational context), then achievement becomes a salient concern for him or her. In this particular context, any stimulus that signals opportunities for or threats to achievement is likely to elicit an emotion (e.g., the clock indicating that he or she is running out of time to complete a specific task). If the person scored low on achievement motivation, or the situation had few achievement characteristics, the same stimulus would be unlikely to elicit an emotion.

Another core assumption of appraisal theories states that emotions are dynamic processes rather than mental states. The emotion process starts with the monitoring and cognitive representation of environmental events. Then events are appraised with regard to personal concerns. Events judged relevant for personal concerns elicit an affective reaction that may include physiological changes, spontaneous expression and subjective feelings. Finally, the affective reaction results in an effort (or at least a desire or motivation) to maintain or change the emotion eliciting situation. Optimally, coping efforts produce the desired changes, so that the emotion process alters its own antecedent conditions.

Mangold et al. (2001) propose that emotions themselves can become an object of appraisal, thereby eliciting meta-emotions. According to this view, the emotion process is exactly the same in primary emotion and in meta-emotion, and only the object of appraisal differs: appraisal of environmental events or media events evokes primary emotions, whereas appraisal of one's own emotions incites meta-emotions (see Bartsch et al., 2006; Jäger \& Bartsch, 2006; and Wirth \& Schramm, 2007 for further elaborations of this approach).

The research literature on meta-emotion supports the idea that the process which gives rise to primary emotions (composed of monitoring, appraisal, affect and coping) may recur 
on a meta-level with regard to one's own emotions. Emotions as such can be monitored and appraised (cf., the meta-evaluation subscales of Mayer \& Stevens, 1994), they may become an object of affective reactions (cf., Oliver, 1993; Williams et al., 1997), which result in a desire to maintain or to change the emotion (cf., the meta-regulation subscales of Mayer \& Stevens, 1994), or in a motivation to approach or avoid emotion-inducing situations and activities in the future (cf., Maio \& Esses, 2001). Thus, appraisal theories of emotion seem well-equipped to cover a large spectrum of the meta-emotion phenomena addressed in the research literature. They also provide a framework for modeling systematic interrelationships between these phenomena by considering them sequential steps in a (meta-)emotion process which conforms to the same process regularities established for primary emotions.

\section{Sharpening the Concept of Meta-Emotion}

Despite the apparent relevance of appraisal theories to explain different aspects of meta-emotion and their causal relationship, two caveats are needed in order to avoid overgeneralization of the concept. First, monitoring and appraisal of emotions do not necessarily lead to meta-emotions. For example, someone can be aware that he or she is angry without experiencing a meta-emotion about it. This complies with appraisal theories of emotion, which assume that concern relevance of events is critical in emotion elicitation. If events are judged irrelevant to one's concerns, appraisal will not lead to an affective reaction. Similarly, meta-emotions only arise if an emotion is appraised to be relevant to personal concerns.

Second, it is important to distinguish between emotion regulation that occurs as a result of a person's effort to change the emotion, and emotion regulation that occurs as a result of a person's effort to change the situation. Changing the situation is often considered to be the ideal means to regulate emotion (cf., Lazarus, 1991). For instance, if a person is angry at someone, expression of his or her anger may change the other person's behavior, so that anger is no longer called for. In this case, emotion regulation is part of the primary 
emotion process. Meta-emotions are involved in emotion regulation only when it comes to altering the spontaneous course of the emotion process in light of the likely outcomes and side effects of that process. For instance, an angry person may worry that anger makes him or her say things that hurt the other person's feelings, so the worry motivates this person to control his or her anger and expressive impulses. In this case, emotion regulation is guided by concerns associated with the meta-emotion (not to hurt the other person's feelings) instead of pursuing concerns associated with the primary emotion (to assert oneself) at any cost.

In view of these caveats concerning the causal link between appraisal, affect and motivation in meta-emotion, it seems useful to distinguish between two kinds of processes:

(1) processes that involve appraisal of emotions as relevant to concerns beyond the scope of the primary emotion, affective reactions toward the primary emotion, and motivation to change the expected course of the primary emotion;

(2) processes that monitor, evaluate and regulate emotions without appraising the emotion as relevant to concerns beyond the scope of the primary emotion and without motivation to change anything about the spontaneous course of that emotion.

We propose the term "meta-emotion" to refer to the first type of processes, since they may be considered as special cases of emotion processes that take other emotions as their intentional objects. This view of meta-emotion as an emotion process is apt to incorporate elements of both the wide and narrow conceptions referred to above without overgeneralizing the concept because it introduces concern relevance of emotions as a core criterion that accounts for evaluative, affective and motivational aspects of meta-emotion and their causal interrelationship. "Emotional intelligence" (Salovey \& Mayer, 1990) provides a useful conceptual framework for the second, predominantly cognitive type of meta-processes. It addresses a broader range of cognitive abilities related to emotions and emphasizes the adaptive function of emotions as such. This distinction may be useful to sharpen the concept 
Appraisal of emotions in media use 14

of meta-emotion and to focus research on concerns that are relevant to individuals' appraisal and regulation of emotions during media use.

A General Process Model of Emotion, Meta-Emotion,

\section{Emotion Regulation and Selective Media Use}

Having laid out an appraisal-theoretical framework for modeling meta-emotion, we will now add specificity to this approach by drawing together research from the domain of emotion psychology on emotionally relevant concerns and research from the field of media psychology on the significance of emotions in shaping media preferences and aversions.

Several authors have argued that appraisal of emotions is an important factor in media effects and selective media use (e.g., Appel, in press; Bartsch et al., 2006; Maio \& Esses, 2001; Oliver, 1993; Sojka \& Giese, 2001; Wirth \& Schramm, 2007). Positive appraisal of emotions during media use is believed to result in a tendency to indulge and enjoy emotions and to seek media offerings that promise similar kinds of emotional experience in the future. Negative appraisal of emotions, in contrast, is thought to motivate suppression of emotions, ending of exposure, and avoidance of similar media experiences.

Drawing on appraisal theories, Bartsch et al. (2006) proposed that appraisal of emotions is as intuitive and effortless as emotion-eliciting appraisal processes are at the level of primary emotions (cf., Lazarus, 1991; Scherer, 2001; Schwartz \& Clore, 1988). Media users need not be consciously aware of the appraisals that give rise to meta-emotions, much like they are often unaware of appraisals that elicit primary emotions. It is assumed that appraisal of emotions relies on the same set of appraisal criteria that evoke primary emotions: Is the emotion novel? Is it pleasant? Is it goal conducive? Is it controllable? Is it normatively adequate? Appraisal of emotions results in an affective reaction toward the primary emotion that integrates different kinds of appraisal information and forms a holistic appraisal outcome (cf., the concept of affect as a holistic appraisal outcome by Schwartz \& Clore, 1988). 
According to Bartsch et al. (2006), selective media use can (in part) be understood as a spontaneous action tendency that stems from affective reactions toward emotions. Just as people use primary emotions to decide intuitively whether to approach or avoid environmental situations, they may use meta-emotions to determine whether they should welcome or reject a media offering's invitation to experience emotion. The authors' concept of selective media use goes beyond selective exposure to media offerings as a whole. It also includes selective exposure to certain stimulus features (e.g., turning the volume up or down), selective adoption of an emotionally involved or distanced mode of reception (cf., Vorderer, 1993), and selective interpretation of symbolic meaning.

As Wirth and Schramm (2007) have pointed out, the valence of meta-emotions is also important for regulating the attentional focus of appraisal processes that give rise to primary emotions. Negative meta-emotions may motivate media users to redirect their attention and change the situational reference of appraisal from media content to other frames of reference associated with more pleasant emotions, for instance, focusing on the reception situation, or on the quality of media content as an artifact (cf., Mangold et al., 2001).

Specific Concerns in Appraisal and Regulation of Emotion during Media Use:

\section{Extending the General Model}

This general model of meta-emotion and emotion regulation in media use deals with the most fundamental aspect of meta-emotion, namely the valence of appraisal, affect, and action tendencies concerning primary emotions. One might object, however, that it fails to use the particular strengths appraisal theories offer in terms of modeling more specific concerns in media users' appraisal and regulation of emotions. Assuming that people like dramas because they like to be sad, or that they like horror-films because they enjoy being shocked, is insufficient if it does not explain what kind of people like which emotions under what conditions and why. 
Appraisal of emotions in media use 16

Appraisal theories are able to answer these questions since they explain how individual disposition and situational context shape concerns, and how concerns influence appraisal of events and resulting emotions. All of these factors are essential for a thorough understanding of meta-emotion and emotion regulation in media use. Without flexible appraisal of emotions, meta-emotions would be hard-wired to the primary emotion and, basically, would explain no more than primary emotions. Without the influence of individual dispositions on appraisal of emotions, it would be difficult to explain why some people love experiencing sadness and empathy through film, whereas others tend to avoid such feelings (cf., Oliver, 1993). Without the influence of situational context, one would be hard pressed to explain why certain emotions are enjoyed in media use but not in everyday life (cf., Vorderer, 2003). We therefore propose an extended model that covers specific concerns and appraisal criteria involved in meta-emotion and allows to predict how and why these criteria are applied to emotions in the context of media use.

Appraisal theories assume that emotion eliciting appraisals are based on a limited set of general concerns (Frijda \& Zeeleberg, 2001; Lazarus, 1991; Scherer, 2001). Although the lists of appraisal criteria proposed by different authors are not identical, general agreement on a set of core dimensions of appraisal exists, including: (1) novelty (events that violate expectations or produce significant changes), (2) intrinsic pleasantness of events, (3) goal conduciveness (potential of events to promote or obstruct the attainment of goals), (4) controllability of events, and (5) norm compatibility. ${ }^{3}$ Each of these general concerns includes an unlimited number of more specific ones (e.g., goal conduciveness includes conduciveness of events to all kinds of goals a person may have). The number of general concerns is limited, however, as appraisal theories aim to make emotions amenable to a comprehensive analysis of underlying concerns using the smallest possible set of general appraisal criteria. This set of appraisal dimensions seems helpful for the study of meta- 
emotion as it allows for a systematic analysis of concerns that might give rise to metaemotions when applied to one's own emotions.

In view of this set of appraisal criteria, a number of previously unrelated research findings on selective media use can be understood more systematically as findings that elucidate concerns which make emotions desirable or undesirable for media users. Further, the findings illustrate how individual disposition and situational context shape appraisal of emotions. We first give an overview of how the application of specific appraisal criteria to emotions sheds light on existing research on selective media use, and then discuss implications for further research.

Appraisal of emotions with regard to novelty: Research on sensation seeking has shown that novelty is a salient concern in people's appraisal of emotions. Sensation seeking is "the seeking of varied, novel, complex and intense sensations and experiences, and the willingness to take ... risks for the sake of such experience.” (Zuckerman, 1994, p. 27). Strong emotions are prime examples of these kind of experiences. Zaleski (1984) found that sensation seekers preferred emotionally intense media stimuli, regardless of valence. Participants with a weak sensation seeking motive, in contrast, preferred neutral and positive stimuli. The strength of the sensation seeking motive may thus be considered as an individual disposition that influences appraisal of emotions with respect to this concern.

Appraisal of emotions with regard to pleasantness: The emotional need that has attracted the most attention and research efforts in the field of media psychology is the hedonistic desire for pleasant experience. This research topic is associated with moodmanagement theory (Zillmann, 1988) which assumes that people prefer an intermediate level of arousal that is experienced as pleasant. People who are bored and under-aroused enjoy emotionally arousing media stimuli, whereas over-aroused or stressed people prefer soothing media stimuli. Multiple studies have tested mood management theory successfully, 
Appraisal of emotions in media use 18

suggesting that a person's prior state of arousal is an important situational factor that determines whether emotions are appraised as being pleasant or unpleasant.

Appraisal of emotions with regard to goal-conduciveness: The significance of events for the attainment of goals constitutes another central concern according to appraisal theories. The concept of mood adjustment (Knobloch-Westerwick \& Alter, 2006), states that goal conduciveness is an important factor in mood regulation as well. Anger, for instance, can be welcome in conflict situations because it helps to command respect. Knobloch-Westerwick and Alter (2006) were able to show that when provoked and offered a future opportunity to retaliate, male participants preferred bad news, which was likely to sustain their moods. This effect was absent in females, which the authors explained in terms of gender-specific norms about expressing anger. This finding illustrates how personal disposition and situational context interact to shape individuals' goals and resulting appraisals of emotions with regard to goal conduciveness. Media users' goals can also pertain to the process of media use as such. The concept of "modes of reception" (Suckfüll, 2004; Vorderer, 1993) refers to such exposure-related goals, for instance, becoming absorbed in the fictional world, identifying with characters, or reflecting on one's own life.

Appraisal of emotions with regard to controllability: A person's sense of control over emotions, or lack thereof, is another important concern when monitoring and evaluating emotions (cf., Gottman et al., 1997; Mayer \& Gaschke, 1988; Salovey et al., 1995). A number of authors have speculated that media use provides a situational context that facilitates control of emotions (e.g., Bartsch et al., 2006; Früh et al., 2004; Mikos, 1996; Vorderer, 2003; Wirth \& Schramm, 2007). To our knowledge, however, the research literature has not yet addressed this hypothesis.

Appraisal of emotions with regard to norm compatibility. Appraisal of emotions with regard to social norms and self-ideals is the only appraisal dimension that has been studied 
explicitly in connection with meta-emotion. According to Oliver (1993; Oliver et al., 2000) gender specific norms and values account for much of the preference for viewing sad films. As predicted, women were more likely to enjoy "chick flicks" and "tearjerkers" than men were. Oliver (1993) explained this in terms of social norms concerning other-directed forms of sadness like empathy, sympathy, and pity. Our culture values other-directed sadness, particularly for the female gender role, whereas more ambivalent evaluations regarding such emotions exist for the gender role of men. Here again, the interaction of personal and situational factors is decisive. Both personal factors (gender-specific norms and values) and situational factors (norms and values concerning other-directed sadness as opposed to selfpity) influence normative appraisal of sadness.

This overview is by no means exhaustive. Nevertheless, it illustrates how appraisal theories can be helpful in connecting previously unrelated research on the role of emotions in media effects and selective media use. However, it is important to emphasize that our interpretation of these results occurred post-hoc, except for the research of Oliver (1993). Thus, in order to establish the role of appraisal and meta-emotion in emotion regulation and media selectivity, additional research that addresses the issue more directly is needed. Nevertheless, it seems fair to speculate that the same set of appraisal criteria widely thought to produce emotions when applied to environmental events can be applied to emotions as well. Furthermore, some preliminary evidence that appraisal of emotions with regard to these criteria guides media users' choices exists. Consistent with the tenets of appraisal theories, appraisal of emotions seems to be determined by an interaction of personal disposition and situational context factors.

Figure 1 summarizes the central tenets of the extended model. It describes a process of appraisal, affect, and action tendencies that starts on the level of primary emotions and recurs on the level of meta-emotions. On the level of primary emotion, media content and/or 
Appraisal of emotions in media use 20

the exposure situation are appraised, and this appraisal results in affective reactions and action tendencies. The whole process of appraisal, affect, and action tendencies (which constitutes the primary emotion) is monitored, appraised, and regulated on a meta-level. Appraisal of emotions is shaped by an interaction of personal disposition and situational context; it takes into account media users' emotional needs and concerns as well as media specific context factors that act as constraints on the pursuit of these concerns. Appraisal of emotions gives rise to affective reactions toward the primary emotion and motivates regulatory efforts. Depending on the valence of meta-emotion, regulatory efforts serve to maintain and approach, or to change and avoid the primary emotion. Emotion regulation can occur via interventions at any stage of the primary emotion process, starting from selective exposure to media content, through changing the focus and content of appraisal, and on to affective and behavioral self-regulation.

-- insert figure 1 about here --

\section{Implications for Future Research}

Besides theoretical integration of existing findings, the extended process model of meta-emotion and emotion regulation has implications for further research. Most important, appraisal theories draw attention to the fact that the viewing motivations and concerns studied in the research literature thus far do not exist in isolation. Media users are not mere sensation seekers, mere hedonists, mere goal rationalists, mere control seekers, or mere norm fulfillers - they pursue all of these concerns simultaneously, only to a varying extent and with varying priorities. Consequently, possible interactions of concerns need to be taken into account when studying the role of emotions in media exposure.

Knobloch-Westerwick and Alter's (2006) study provides an example of this methodical imperative. By considering the role of pleasantness, goal conduciveness and normative adequacy as interacting concerns (albeit not from an appraisal-theoretical 
Appraisal of emotions in media use 21

perspective), these authors were able to explain the mixed results obtained by earlier moodmanagement studies (Biswas, Riffe \& Zillmann, 1994; Medoff, 1979). Biswas et al. (1994), for instance, found that women's news preferences, but not those of men, followed predictions of mood-management theory when frustrating test feedback was used to induce mood. By taking into account gender differences in normative adequacy and by manipulating goal conduciveness, Knobloch-Westerwick and Alter (2006) showed that the combined effect of anger being goal conducive and normatively adequate was strong enough to override the hedonistic concern to terminate unpleasant feelings as soon as possible.

A systematic checklist of appraisal criteria makes it easier to foresee such interactions of concerns and to avoid confounding their contribution to emotional media effects and selective media use. In order to do so, the concerns and interactions under study need to be manipulated systematically, while appraisal of emotions with regard to other concerns remains constant. In addition, it would be helpful to use introspective measures alongside experimental manipulation in order to provide a manipulation check that will support the interpretation of results and eventually helps interpret unexpected findings. As Wirth and Schramm (2007) have argued, the meta-evaluation subscales of the State Meta-Mood Scale (Mayer \& Stevens, 1994) may be re-interpreted in light of appraisal theories, thus providing a preliminary approach to measure appraisal of emotions. ${ }^{4}$ This post-hoc interpretation needs to be treated with caution, however, and accompany theory-driven scale development.

The extended process model further helps to generate new hypotheses and research questions about the role of emotions in media use as it points to concerns and influence factors that have been neglected in the research literature thus far. Individuals' sense of control over emotions provides an example of a concern that merits further attention and research efforts. For instance, it can be hypothesized that a strong sense of control over emotions (for psychometric approaches see Catanzaro \& Mearns, 1990; Gratz \& Roemer, 
2004) is associated with higher levels of preference for and enjoyment of emotionally challenging media genres like horror, thriller, and tear-jerker. It also seems worthwhile to consider the context sensitivity of controllability appraisals (i.e., individuals' sense of control over emotions in the context of media use as opposed to every day life). A combination of low controllability of emotions in everyday life and high controllability of emotions in the context of media use should be particularly predictive of media preference and enjoyment (for a more detailed argument concerning this hypothesis see Vorderer, 2003).

Besides studying new concerns in individuals' appraisal and regulation of emotions, the study of already established concerns may profit from paying greater attention to the context sensitivity of emotion-related appraisals. In the same line of reasoning as for controllability, differences on other appraisal dimensions may be predicted, since it is often assumed that emotions are appraised more favorably in the context of media use than in everyday life (see Bartsch \& Viehoff, 2003; Früh et al., 2004; Vorderer, 2003). To substantiate this hypothesis, more research is needed that addresses the role of the media in providing their audiences with an opportunity to indulge and enjoy emotions they would otherwise avoid.

\section{Summary}

This paper began with an overview of the active and rapidly growing research on meta-emotion and related constructs, especially but not exclusively in the field of media psychology. The basic idea behind the concept, which states that people experience, evaluate and deal with emotion in significantly different ways, has been tested successfully. It has also proven useful in terms of explanatory power and predictive validity across a number of research topics. Despite the apparent success of the concept, we also observed some problems, particularly concerning the lack of consensus on how to define and operationalize meta-emotion. 
Appraisal of emotions in media use 23

The wealth of largely unrelated definitional and empirical approaches led us to revisit meta-emotion in the context of general emotion theory. We introduced a theoretical framework for modeling meta-emotion based on appraisal theories, which seem well-suited to integrate multiple aspects of meta-emotion discussed in the research literature.

Nevertheless it is important not to overgeneralize the concept and the causal relationship of phenomena implied. In order to sharpen the concept of meta-emotion, we introduced concern relevance of emotions as a core criterion that accounts for the causal relationship of evaluative, affective and motivational aspects of meta-emotion and distinguishes the concept from predominantly cognitive forms of monitoring, appraising, and regulating emotion.

Building on recent theoretical work of Mangold et al. (2001), Bartsch et al. (2006) and Wirth and Schramm (2007), we proposed an extended process model of meta-emotion in media use that covers specific concerns involved in individuals' appraisal and regulation of emotions and highlights the role of individual disposition and situational context in shaping emotion-related appraisals. Our theoretical framework synthesizes previously unrelated research findings on the role of emotions in guiding selective media use. Besides theoretical integration of existing findings, implications of the model for further research were discussed. We suggest that concerns like novelty, pleasantness, goal conduciveness, controllability and normative adequacy of emotions should not be studied in isolation. Rather, they need to be considered as interacting concerns which shape media users' preferences and aversions. Finally, the model draws attention to previously neglected research topics, such as media users' sense of control over emotions, or the role of the media in providing their audiences with a context that invites a re-appraisal of emotions and fosters their willingness and ability to indulge and enjoy emotions they would otherwise avoid. 
Appraisal of emotions in media use 24

\section{References}

Appel, M. (in press). Manche mögen's heiß. Ergebnisse der deutschsprachigen Version eines Instruments zur Erfassung des Emotionsmotivs. [Some like it hot. Results of the German language version of an instrument aimed at the assessment of the need for affect/need for emotion.] Diagnostica.

Bartsch, A. (2007). Meta-emotion during film and music-video reception. Developing a statemeasure of liking/disliking emotions. Paper presented at the ICA Conference 2007, San Francisco, USA.

Bartsch, A., Mangold, R., Viehoff, R., \& Vorderer P. (2006). Emotional gratifications during media use - an integrative approach. Communications, 31, 261-278.

Bartsch, A. \& Viehoff, R. (2003). Meta-emotion: In search of a meta-account for entertainment by negative emotions. Siegener Periodikum zur Internationalen Empirischen Literaturwissenschaft, 22, 309-328.

Biswas, R., Riffe, D., \& Zillmann, D. (1994). Mood influence on the appeal of bad news. Journalism Quarterly, 71, 689-696.

Booth-Butterfield, M., \& Booth-Butterfield, S. (1990). Conceptualizing affect as information in communication production. Human Communication Research. 16, 451-476.

Byrne, D. (1961). The repression-sensitization scale: Rationale, reliability, and validity. Journal of Personality, 29, 334-349.

Catanzaro, S. J., \& Mearns, J. (1990). Measuring generalized expectancies for negative mood regulation: Initial scale development and implications. Journal of Personality Assessment, 54, 546-563.

Ellis, R. D. (2005). The roles of imagery and meta-emotion in deliberate choice and moral psychology. Journal of Consciousness Studies, 12, 140-157. 
Appraisal of emotions in media use 25

Folkman, S., \& Lazarus, R. S. (1985). If it changes it must be a process: Study of emotion and coping during three stages of a college examination. Journal of Personality and Social Psychology, 48, 150-170.

Frijda, N. H. \& Zeelenberg, M. (2001). Appraisal: What is the dependent? In K. R. Scherer, A. Schorr \& T. Johnstone (Eds.), Appraisal processes in emotion (pp. 141-157). Oxford: Oxford University Press.

Früh, W., Wünsch, C., \& Klopp, P. (2004). TDU-Unterhaltungsindex. Ein Instrument zur empirischen Ermittlung von Unterhaltungserleben [TDU-Entertainment-Index. An instrument for the empirical measurement of entertainment experience]. Medien und Kommunikationswissenschaft, 4, 515-544.

Gottman, J. M. (1994). What Predicts Divorce? The Relationship between Marital Process and Marital Outcomes. Hillsdale, NJ: Erlbaum.

Gottman, J. M., Katz, L. F. \& Hooven, C. (1997). Meta-emotion: How families communicate emotionally. Mahwah, NJ: Erlbaum.

Gratz, K. L., \& Roemer, L. (2004). Multidimensional assessment of emotion regulation and dysregulation: Development, factor structure, and initial validation of the difficulties in emotion regulation scale. Journal of Psychopathology \& Behavioral Assessment, 26, 41-54.

Jäger, C. \& Bartsch, A. (2006). Meta-emotions. Grazer Philosophische Studien, 73, 179-204. Jakupcak, M. (2003). Masculine gender role stress and men's fear of emotions as predictors of self-reported aggression and violence. Violence and Victims, 18, 533-541.

Knobloch-Westerwick, S. \& Alter, S. (2006). Mood adjustment to social situations through mass media use: How men ruminate and women dissipate angry moods. Human Communication Research, 32, 58-73.

Lazarus, R. S. (1991). Emotion and adaptation. Oxford: Oxford University Press. 
Appraisal of emotions in media use 26

Maio, G. R. and Esses, V. M. (2001). The need for affect: Individual differences in the motivation to approach or avoid emotions. Journal of Personality, 69, 583-615.

Mangold, R., Unz, D., and Winterhoff-Spurk, P. (2001). Zur Erklärung emotionaler Medienwirkungen: Leistungsfähigkeit, empirische Überprüfung und Fortentwicklung theoretischer Ansätze [Explaining emotional media effects: Efficiency, empirical testing, and further development of theoretical approaches]. In P. Rössler, U. Hasenbrink, and M. Jäckel (Eds.), Theoretische Perspektiven der Rezeptionsforschung (pp. 163-180). Munich: Reinhard Fischer.

Mayer, J. D. and Gaschke, Y. N. (1988). The experience and meta-experience of mood. Journal of Personality and Social Psychology, 55, 105-111.

Mayer, J. D., Salovey, P., \& Caruso, D. R. (2002). Mayer-Salovey-Caruso Emotional Intelligence Test (MSCEIT) User's Manual. Toronto, Canada: MHS Publishers.

Mayer, J. D., \& Stevens, A. (1994). An emerging understanding of the reflective (meta-) experience of mood. Journal of Research in Personality, 28, 351-373.

Medoff, N. J. (1979). The avoidance of comedy by persons in a negative affective state: A further study in selective exposure. Unpublished doctoral dissertation, Indiana University, Bloomington, IN.

Mikos, L. (1996). The experience of suspense: Between fear and pleasure. In P. Vorderer \& M. Friedrichsen (Eds.), Suspense: Conceptualizations, theoretical analyses, and empirical explorations. Mahwah, NJ: Lawrence Erlbaum.

Oatley, K. \& Jenkins, J.M. (1996). Understanding Emotions. Cambridge, MA: Blackwell.

Oliver, M. B. (1993). Exploring the paradox of the enjoyment of sad films. Human Communication Research, 19, 315-342. 
Appraisal of emotions in media use 27

Oliver, M. B., Weaver, J. B., \& Sargent, S. L. (2000). An examination of factors related to sex differences in enjoyment of sad film. Journal of Broadcasting and Electronic Media, 44, 282-300.

Prairie, E. M. (2004). Emotional communication in the family of origin of women with borderline personality disorder. Dissertation, University of Massachusetts Amherst.

Raman, N. V., Chattopadhyay, P., \& Hoyer, W. D. (1995). Do consumers seek emotional situations: The need for emotion scale. Advances in Consumer Research, 22, 537-542.

Roemer, L., Salters, K., Raffa, S., \& Orsillo, S. M. (2005). Fear and avoidance of internal experiences in GAD: preliminary tests of a conceptual model. Cognitive Therapy and Research, 29, 71-88.

Rosenman, S. (Ed.) (1938). The Public Papers of Franklin D. Roosevelt, Volume Two: The Year of Crisis, 1933. New York: Random House.

Salovey, P. \& Mayer, J.D. (1990). Emotional intelligence. Imagination, Cognition, and Personality, 9, 185-211.

Salovey, P., Mayer, J. D., Goldman, S., Turvey, C, \& Palfai, T. (1995). Emotional attention, clarity, and repair: Exploring emotional intelligence using the Trait Meta-Mood Scale. In J. W. Pennebaker (Ed.) Emotion, disclosure, and health (pp. 125-154). Washington, D.C.: American Psychological Association.

Salovey, P., Stroud, L. R., Woolery, A., \& Epel, E. S. (2002). Perceived emotional intelligence, stress reactivity, and symptom reports: Further explorations using the trait meta-mood-scale. Psychology and Health, 17, 661-627.

Scherer, K. R. (2001). Appraisal considered as a process of multilevel sequential checking. In K. R. Scherer, A. Schorr \& T. Johnstone (Eds.), Appraisal processes in emotion (pp. 92-120). New York: Oxford University Press. 
Appraisal of emotions in media use 28

Schwartz, N. \& Clore, G. L. (1988). How do I feel about it? The informative function of mood. In K. Fiedler \& J. Forgas (Eds.), Affect, cognition, and social behavior (pp. 4462). Toronto: Hogrefe.

Sojka, J. Z., \& Giese, J. L. (1997). Thinking and/or feeling: An examination of interaction between processing styles. Advances in Consumer Research, 24, 438-442.

Sojka, J. Z., \& Giese, J. L. (2001). The influence of personality traits on the processing of visual and verbal information. Marketing Letters, 12, 1.

Suckfüll, M. (2004). Rezeptionsmodalitäten. Ein integratives Konstrukt für die Medienwirkungsforschung [Modes of reception. An integrative construct for media effects research]. Munich: Reinhard Fischer.

Taylor, G. J., Ryan, D., \& Bagby, R. M. (1985). Toward the development of a new self-report alexithymia scale. Psychotherapy and Psychosomatics, 44, 191-199.

Vorderer, P. (1993). Audience involvement and program loyalty. Poetics. Journal of Empirical Research on Literature, Media and the Arts, 22, 89-98.

Vorderer, P. (2003). Entertainment theory. In J. Bryant, D. Roskos-Ewoldsen \& J. Cantor (Eds.), Communication and emotion: Essays in honor of Dolf Zillmann (pp. 131-153). Mahwah, NJ: Lawrence Erlbaum Associates.

Williams, K. E., Chambless, D. L., \& Ahrens, A. (1997). Are emotions frightening? An extension of the fear of fear construct. Behaviour Research and Therapy, 35, 239248.

Wirth, W., \& Schramm, H. (2007). Emotionen, Metaemotionen und Regulationsstrategien bei der Medienrezeption. Ein integratives Modell. In W. Wirth, H.-J. Stiehler, \& C. Wünsch (Eds.), Dynamisch-transaktional denken: Theorie und Empirie in der Kommunikationswissenschaft (pp. 153-184). Köln: Halem. 
Appraisal of emotions in media use 29

Zaleski, Z. (1984). Sensation seeking and preference for emotional visual stimuli. Personality and Individual Differences, 5, 609-611.

Zillmann, D. (1988). Mood management through communication choices. American Behavioral Scientist, 31, 327-340.

Zuckerman, M. (1994). Behavioral expressions and biosocial bases of sensation seeking. New York: Cambridge University Press. 
Appraisal of emotions in media use 30

\section{Footnotes}

${ }^{1}$ The authors wish to thank Robin Nabi and the anonymous reviewers for their helpful comments on earlier drafts of this paper.

${ }^{2}$ Source: Franklin D. Roosevelt, Inaugural Address, March 4, 1933, in S. Rosenman, (Ed.) (1938, pp. 11-16).

${ }^{3}$ Further appraisal criteria like certainty (that the event has occurred or will occur) and causal agency (who or what is responsible for producing the event) are sometimes considered as concerns on their own right, and sometimes as "subchecks" of the controllability appraisal (cf., Scherer, 2001). For the sake of simplicity, they will not be considered in detail here.

${ }^{4}$ Wirth \& Schramm (2007) proposed to interpret the Acceptability dimension of the State Meta-Mood Scale as a pleasantness appraisal of emotions, Typicality as a (reverse scored) novelty appraisal, and Influence as a controllability appraisal. The items of the Acceptance subscale (e.g., "I shouldn't feel this way.”, "I'm not ashamed of my mood.") might alternatively be interpreted as an appraisal of normative adequacy. Interpretation of the Influence subscale as a controllability appraisal of emotions is not entirely unproblematic as well because the items (e.g., "It [the mood] has altered my outlook.", "It's changed how I think.") refer to the influence of moods on the person's thinking rather than to the person's influence on his or her mood. 
Table 1. Characteristics of existing operationalizations of meta-emotion and related constructs.

\begin{tabular}{|c|c|c|c|c|c|c|c|c|c|c|}
\hline $\begin{array}{l}\text { narrow definition wide } \\
\text { definition } \\
\text { narrow definition }\end{array}$ & $\begin{array}{l}\text { wide } \\
\text { defin } \\
\text { ition }\end{array}$ & state & trait & $\begin{array}{l}\text { spec } \\
\text { ific } \\
\text { prim } \\
\text { ary } \\
\text { emot } \\
\text { ion }\end{array}$ & $\begin{array}{l}\text { emot } \\
\text { ions } \\
\text { in } \\
\text { gene } \\
\text { ral }\end{array}$ & $\begin{array}{l}\text { spec } \\
\text { ific } \\
\text { cont } \\
\text { ext }\end{array}$ & $\begin{array}{l}\text { inde } \\
\text { pend } \\
\text { ent } \\
\text { of } \\
\text { cont } \\
\text { ext }\end{array}$ & $\begin{array}{l}\text { spec } \\
\text { ific } \\
\text { cont } \\
\text { ent } \\
\text { of } \\
\text { meta } \\
- \\
\text { emot } \\
\text { ion }\end{array}$ & $\begin{array}{l}\text { vale } \\
\text { nce } \\
\text { of } \\
\text { meta } \\
- \\
\text { emot } \\
\text { ion }\end{array}$ & $\begin{array}{l}\text { Sa } \\
\text { d } \\
\text { Film } \\
\text { Scal } \\
\text { e } \\
\text { Sad } \\
\text { Film } \\
\text { Scal } \\
\text { e } \\
\text { Olive } \\
r \\
\text { (199 } \\
\text { 3) }\end{array}$ \\
\hline $\begin{array}{l}\text { State Meta-Mood Scale } \\
\text { Mayer \& Stevens (1994) }\end{array}$ & & $x$ & $x$ & & & $x$ & & $x$ & $x$ & \\
\hline $\begin{array}{l}\text { Trait Meta-Mood Scale } \\
\text { Salovey et al. (1995) }\end{array}$ & & $x$ & & $x$ & & $x$ & & $x$ & $x$ & \\
\hline $\begin{array}{l}\text { Need for Emotion } \\
\text { Raman et al. (1995) }\end{array}$ & $x$ & & & $x$ & & $x$ & & $x$ & & $x$ \\
\hline $\begin{array}{l}\text { Meta-Emotion Interview } \\
\text { Gottman et al. (1997) }\end{array}$ & $x$ & & & $x$ & $x$ & & & $x$ & $x$ & \\
\hline $\begin{array}{l}\text { Affect Control Scale (fear of emotions) } \\
\text { Williams et al. (1997) }\end{array}$ & $x$ & & & $x$ & $x$ & & & $x$ & $x$ & \\
\hline $\begin{array}{l}\text { Need for Affect } \\
\text { Sojka \& Giese (1997) }\end{array}$ & $x$ & & & $x$ & & $x$ & & $x$ & & $x$ \\
\hline $\begin{array}{l}\text { Need for Affect } \\
\text { Maio \& Esses (2001) }\end{array}$ & $x$ & & & $x$ & & $x$ & & $x$ & & $x$ \\
\hline $\begin{array}{l}\text { Entertainment Index (macro-emotion) } \\
\text { Früh et al. (2004) }\end{array}$ & $x$ & & $x$ & & & $x$ & $x$ & & $x$ & \\
\hline
\end{tabular}


Appraisal of emotions in media use 32

Figure 1

An extended process model of emotion, meta-emotion, and emotion regulation in media use.

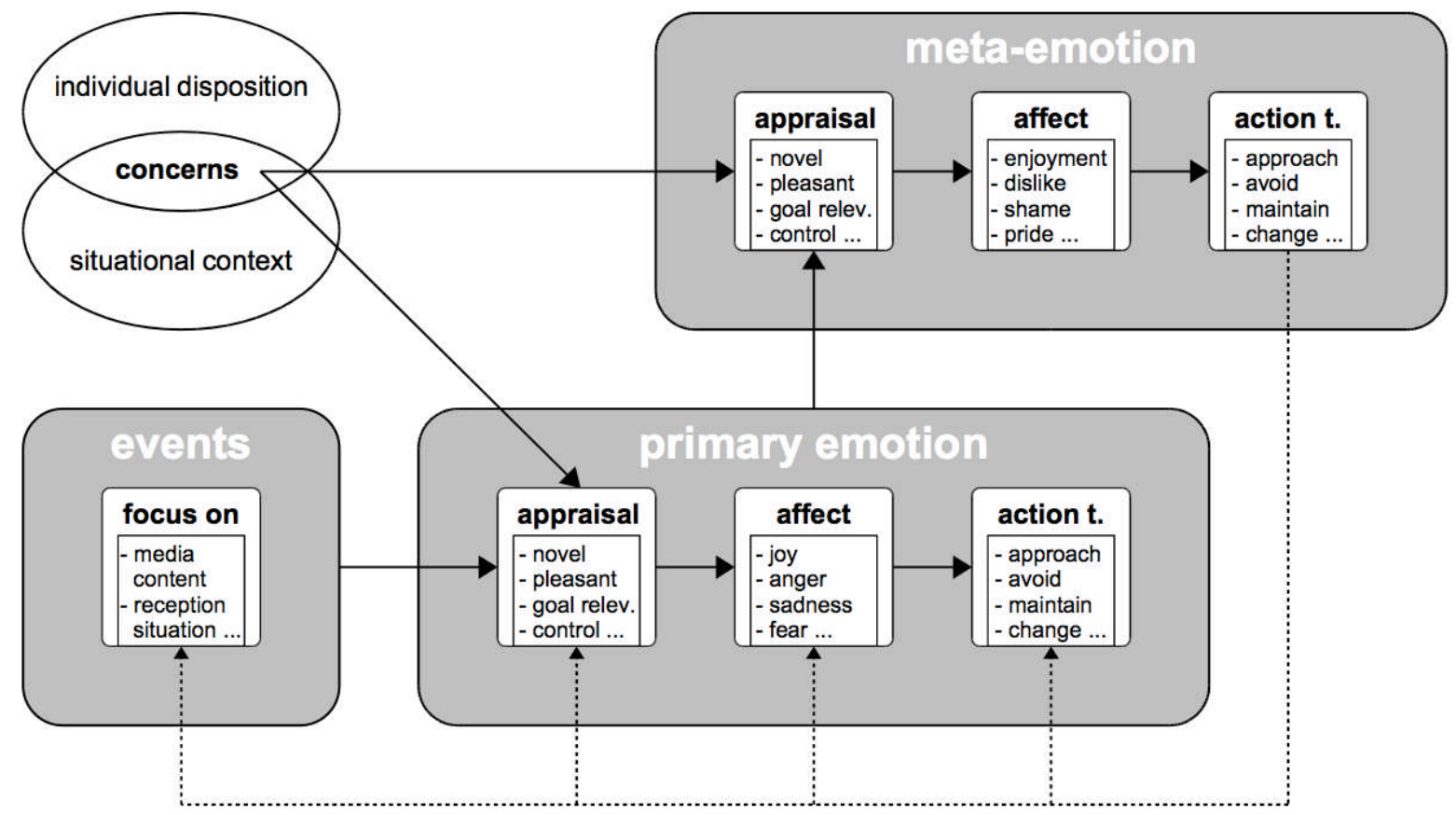

